\title{
Studying Effect of Fe Doping on the Structural Properties and Infrared Spectroscopy of Tin Oxide powders by Solid State Reaction Method
}

\author{
Abeer Najjar $^{1 *} \quad$ Ahmad Khdro $^{2} \quad$ Talal khalas ${ }^{3}$ \\ 1.MSc Student, Department of Physics, Faculty of science, Tishreen University, Syria \\ 2.Professor, Department of Physics, Faculty of science, Tishreen University, Syria \\ 3.Assistant Professor, Department of Physics, Faculty of science, Tishreen University, Syria
}

\begin{abstract}
Fe doped tin oxide transparent conducting powder were prepared by solid state reaction method. Structural properties of the samples were investigated as a function of various Fe-doping levels $(x=0.00-0.01-0.03-0.05-$ $0.06)$. The results of $x$-ray diffraction have shown that the samples are polycrystalline structure in tetragonal phase with preferential orientations along the (110) for all samples The relative intensities, distance between crystalline planes (d), crystallite size (D), dislocation density ( $\delta$ ) and lattice parameters (a), (c) were determined. Infrared Spectroscopy have been studied by Infrared Spectrometer Device.
\end{abstract}

Keywords: powder, Iron doped Tin Oxide, solid state reaction, Structural properties, Infrared Spectroscopy.

DOI: $10.7176 / \mathrm{CMR} / 11-4-01$

Publication date: April $30^{\text {th }} 2019$

\section{Introduction}

Transparent conducting oxides (TCOs) are semiconductors that are produced from a combination of metal and oxygen such as: $\mathrm{ZnO}, \mathrm{In}_{2} \mathrm{O}_{3}, \mathrm{SnO}_{2}$. The studying of TCOs is very important because of their special properties that is used in technology applications [1].

Tin oxide $\left(\mathrm{SnO}_{2}\right)$ is considered as one of the most important member of the TCOs for its unique electrical and optical properties because it has low electrical resistivity, high optical transparency in visible region, high optical reflectance in infrared region and chemical inertness. So, $\mathrm{SnO} 2$ is used in solar cells, sensor gas, display devices and in other important applications [2].

$\mathrm{SnO}_{2}$ is an n-type semiconductor with wide band gap energy $(\mathrm{Eg}=3.5-4 \mathrm{eV})[3] . \mathrm{SnO}_{2}$ has tetragonal structure belonging to the $\mathrm{P} 42 / \mathrm{mnm}$ space group. The lattice parameters are $\mathrm{a}=\mathrm{b}=4.7382$ and $\mathrm{c}=3.1871 \mathrm{~A}$ [4]. Its unit cell contains two tin and four oxygen atoms as is shown in figure 1. The tin atom is at the center of six oxygen atoms placed at the corners of a regular octahedron. Every oxygen atom is surrounded by three tin atoms at the corners of an equilateral triangle $[5,6]$.

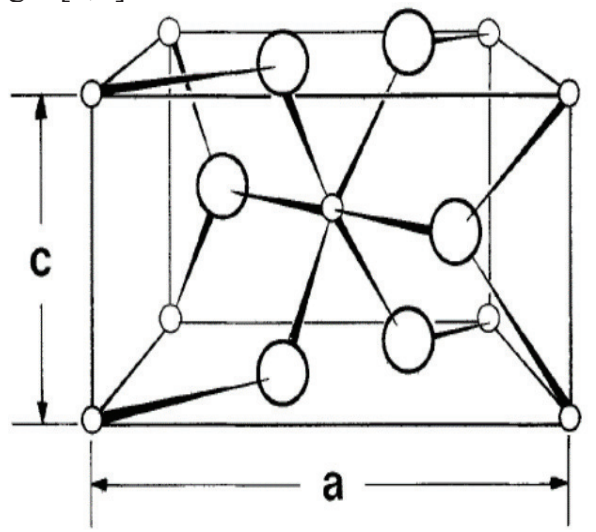

Fig. 1: Unit cell of the crystal structure of $\mathrm{SnO}_{2}$. Large circles indicate oxygen atoms and the small circles indicate tin atoms.

\section{2 .Experimental Method}

$\mathrm{Sn}_{1-\mathrm{x}} \mathrm{Fe}_{\mathrm{x}} \mathrm{O}_{2}$ powders $(\mathrm{x}=0.00 .0 .01,0.03,0.05,0.06)$ were prepared by a solid state reaction method. were accurately weighed in required proportions and were mixed and ground thoroughly using an Agate mortar and pestle to convert to very fine powders.

The grinding of the mixtures was carried out for 3 hours for all the powder samples. The ground powder samples were firing at $700^{\circ} \mathrm{C}$ for 3 hours. 


\section{3 .Results and discussions}

3.1 Structural properties

The X-ray diffraction patterns of undoped and $\mathrm{Fe}$ doped $\mathrm{SnO}_{2}$ powders prepared with various Fe concentration 0 wt $\%, 1 \mathrm{wt} \%, 3 \mathrm{wt} \%, 5 \mathrm{wt} \%$ and $6 \mathrm{wt} \%$ are shown in Fig. 2.

The XRD reveals that all samples are having polycrystalline nature with tetragonal structure and peaks correspond to $(110),(101),(200),(111),(210),(211),(220),(002),(310),(112),(301),(202)$ and (321) planes. The preferred orientation is (110) for all samples. We noticed disappearance of these orientations (111),(210), (301) in all doped samples.

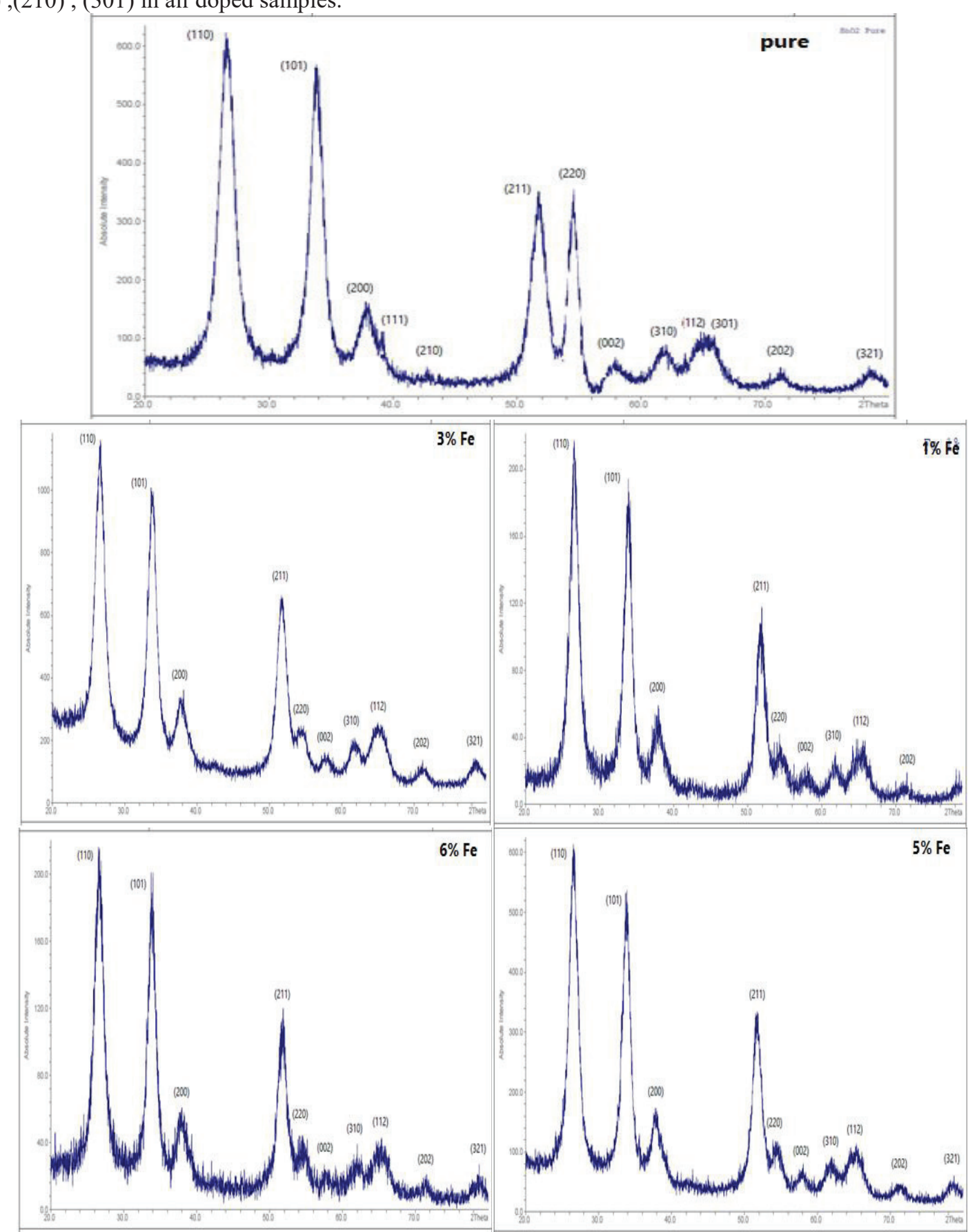

Fig. 2: XRD results of pure $\mathrm{SnO}_{2}, 1$ wt $\%$ Fe doped $\mathrm{SnO}_{2}, 3$ wt $\%$ Fe doped $\mathrm{SnO}_{2}, 5$ wt $\%$ Fe doped $\mathrm{SnO}_{2}, 6$ wt $\%$ $\mathrm{Fe}$ doped $\mathrm{SnO}_{2}$. 
Table (1) shows results of structural values of undoped $\mathrm{SnO}_{2}$ sample.

\begin{tabular}{|c|c|c|c|c|c|c|c|c|c|c|}
\hline \multicolumn{11}{|c|}{ Table (1) } \\
\hline \multirow[t]{2}{*}{ samples } & \multirow[t]{2}{*}{$\begin{array}{c}2 \theta \\
\text { (deg) }\end{array}$} & \multirow[t]{2}{*}{ )hkl( } & \multirow[t]{2}{*}{$\begin{array}{c}d \\
\left(A^{\circ}\right)\end{array}$} & \multirow{2}{*}{$\begin{array}{l}\text { Rel. } \\
\text { int. } \\
{[\%]}\end{array}$} & \multirow[t]{2}{*}{$\begin{array}{c}\beta \\
(\operatorname{deg})\end{array}$} & \multirow[t]{2}{*}{$\stackrel{\text { D }}{(\mathrm{nm})}$} & \multirow[t]{2}{*}{$\begin{array}{c}\text { Average } \\
\text { D(nm) }\end{array}$} & \multirow{2}{*}{$\begin{array}{c}\delta \\
10^{15} \text { line } / \mathrm{m}^{2}\end{array}$} & \multicolumn{2}{|c|}{$\begin{array}{l}\text { Lattice } \\
\text { const. }\end{array}$} \\
\hline & & & & & & & & & $\mathrm{a}(\AA)$ & $\mathbf{c}(\AA)$ \\
\hline \multirow{14}{*}{$\begin{array}{l}\mathrm{SnO}_{2} \\
\text { pure }\end{array}$} & 26.62 & (110) & 3.348 & 100 & 1.392 & 6.128 & \multirow{14}{*}{11.877} & & \multirow{14}{*}{4.733} & \multirow{14}{*}{3.185} \\
\hline & & & & & & & & 26.628 & & \\
\hline & 33.99 & (101) & 2.637 & 87 & 1.391 & 6.240 & & 25.680 & & \\
\hline & 37.95 & (200) & 2.370 & 25 & 0.886 & 9.908 & & 10.187 & & \\
\hline & 38.96 & (111) & 2.311 & 7 & 0.440 & 20.012 & & 2.497 & & \\
\hline & 42.62 & (210) & 2.121 & 4 & 0.510 & 17.471 & & 3.276 & & \\
\hline & 51.87 & (211) & 1.762 & 58 & 1.265 & 7.297 & & 18.783 & & \\
\hline & 54.75 & (220) & 1.676 & 58 & 0.506 & 18.473 & & 2.930 & & \\
\hline & 57.87 & (002) & 1.593 & 11 & 1.012 & 9.372 & & 11.385 & & \\
\hline & 61.99 & (310) & 1.497 & 14 & 1.341 & 7.221 & & 19.180 & & \\
\hline & 64.84 & $(112)$ & 1.437 & 17 & 1.898 & 5.180 & & 37.261 & & \\
\hline & 65.96 & (301) & 1.416 & 15 & 0.632 & 15.656 & & 4.080 & & \\
\hline & 71.25 & (202) & 1.323 & 7 & 1.645 & 6.207 & & 25.955 & & \\
\hline & 78.30 & (321) & 1.221 & 10 & 0.424 & 25.240 & & 1.570 & & \\
\hline
\end{tabular}

Table (2) shows results of structural values of Fe doped $\mathrm{SnO}_{2}$ samples $(\mathrm{x}=0.01-0.03)$.

\begin{tabular}{|c|c|c|c|c|c|c|c|c|c|c|}
\hline \multicolumn{11}{|c|}{ Table (2) } \\
\hline \multirow{2}{*}{ samples } & \multirow{2}{*}{$\begin{array}{c}2 \theta \\
(\mathrm{deg})\end{array}$} & \multirow[t]{2}{*}{ )hkl( } & \multirow[t]{2}{*}{$d\left(A^{\circ}\right)$} & \multirow{2}{*}{$\begin{array}{l}\text { Rel. } \\
\text { int. } \\
{[\%]}\end{array}$} & \multirow{2}{*}{$\begin{array}{c}\beta \\
(\operatorname{deg})\end{array}$} & \multirow{2}{*}{$\begin{array}{c}D \\
(\mathrm{~nm})\end{array}$} & \multirow{2}{*}{$\begin{array}{c}\text { Average } \\
\text { D(nm) }\end{array}$} & \multirow{2}{*}{$\begin{array}{c}\delta \\
10^{15} \text { line } / \mathrm{m}^{2}\end{array}$} & \multicolumn{2}{|c|}{ Lattice const. } \\
\hline & & & & & & & & & $\mathbf{a}(\AA)$ & $\mathbf{c}(\AA)$ \\
\hline \multirow{9}{*}{$\begin{array}{l}\mathrm{SnO}_{2}: \mathrm{Fe} \\
(1 \mathrm{wt} \%)\end{array}$} & 26.50 & $(110)$ & 3.362 & 100 & 1.375 & 6.202 & \multirow{9}{*}{7.230} & 25.994 & \multirow{9}{*}{4.755} & \multirow{9}{*}{3.179} \\
\hline & 34.01 & (101) & 2.635 & 89 & 1.300 & 6.677 & & 22.427 & & \\
\hline & 37.88 & (200) & 2.375 & 26 & 1.500 & 5.851 & & 29.213 & & \\
\hline & 51.88 & (211) & 1.762 & 53 & 1.620 & 5.698 & & 30.803 & & \\
\hline & 54.38 & (220) & 1.687 & 20 & 1.120 & 8.332 & & 14.406 & & \\
\hline & 57.99 & $(002)$ & 1.590 & 11 & 1.300 & 7.300 & & 18.766 & & \\
\hline & 61.75 & $(310)$ & 1.502 & 18 & 1.000 & 9.671 & & 10.693 & & \\
\hline & 64.70 & (112) & 1.440 & 15 & 1.750 & 5.614 & & 31.726 & & \\
\hline & 71.25 & (202) & 1.323 & 5 & 1.050 & 9.724 & & 10.575 & & \\
\hline \multirow{10}{*}{$(3 \mathrm{wt} \%)$} & 26.50 & $(110)$ & 3.362 & 100 & 1.720 & 4.958 & \multirow{10}{*}{7.446} & 40.675 & \multirow{10}{*}{4.755} & \multirow{10}{*}{3.181} \\
\hline & 33.98 & (101) & 2.637 & 80 & 1.500 & 5.787 & & 29.863 & & \\
\hline & 37.75 & (200) & 2.382 & 29 & 1.500 & 5.849 & & 29.235 & & \\
\hline & 51.75 & (211) & 1.766 & 57 & 1.700 & 5.427 & & 33.956 & & \\
\hline & 54.37 & (220) & 1.687 & 20 & 1.000 & 9.331 & & 11.485 & & \\
\hline & 57.90 & $(002)$ & 1.592 & 13 & 1.000 & 9.486 & & 11.114 & & \\
\hline & 61.60 & $(310)$ & 1.505 & 18 & 1.370 & 7.053 & & 20.100 & & \\
\hline & 65.12 & (112) & 1.432 & 22 & 1.750 & 5.627 & & 31.579 & & \\
\hline & 71.05 & (202) & 1.326 & 10 & 0.950 & 10.735 & & 8.678 & & \\
\hline & 78.50 & $(321)$ & 1.218 & 11 & 1.050 & 10.207 & & 9.599 & & \\
\hline
\end{tabular}


Table (3) shows results of structural values of Fe doped $\mathrm{SnO}_{2}$ samples $(\mathrm{x}=0.05-0.06)$.

\begin{tabular}{|c|c|c|c|c|c|c|c|c|c|c|}
\hline \multicolumn{11}{|c|}{ Table (3) } \\
\hline \multirow{2}{*}{ samples } & \multirow{2}{*}{$\begin{array}{c}2 \theta \\
(\operatorname{deg})\end{array}$} & \multirow{2}{*}{ )hkl( } & \multirow{2}{*}{ d $\left(A^{\circ}\right)$} & \multirow{2}{*}{$\begin{array}{l}\text { Rel. } \\
\text { int. } \\
{[\%]}\end{array}$} & \multirow{2}{*}{$\begin{array}{c}\beta \\
(\operatorname{deg})\end{array}$} & \multirow{2}{*}{ D (nm) } & \multirow{2}{*}{$\begin{array}{c}\text { Average } \\
\text { D(nm) }\end{array}$} & \multirow{2}{*}{$\begin{array}{c}\delta \\
10^{15} \text { line } / \mathrm{m}^{2}\end{array}$} & \multicolumn{2}{|c|}{ Lattice const. } \\
\hline & & & & & & & & & $\mathbf{a}(\AA)$ & $\mathbf{c}(\AA)$ \\
\hline \multirow{10}{*}{$(5 \mathrm{wt} \%)$} & 26.52 & $(110)$ & 3.360 & 100 & 1.500 & 5.686 & \multirow{10}{*}{7.004} & 30.932 & \multirow{10}{*}{4.751} & \multirow{10}{*}{3.176} \\
\hline & 33.88 & (101) & 2.645 & 84 & 1.370 & 6.334 & & 24.925 & & \\
\hline & 37.86 & (200) & 2.376 & 29 & 1.250 & 7.021 & & 20.289 & & \\
\hline & 51.88 & (211) & 1.762 & 54 & 1.420 & 6.500 & & 23.666 & & \\
\hline & 54.24 & $(220)$ & 1.691 & 19 & 1.250 & 7.461 & & 17.965 & & \\
\hline & 58.06 & $(002)$ & 1.588 & 12 & 1.120 & 8.476 & & 13.920 & & \\
\hline & 62.06 & $(310)$ & 1.495 & 15 & 1.750 & 5.535 & & 32.640 & & \\
\hline & 65.36 & (112) & 1.427 & 17 & 1.750 & 5.635 & & 31.494 & & \\
\hline & 71.74 & (202) & 1.315 & 7 & 1.000 & 10.242 & & 9.533 & & \\
\hline & 78.54 & (321) & 1.217 & 8 & 1.500 & 7.147 & & 19.579 & & \\
\hline \multirow{10}{*}{ (6 wt $\%)$} & 26.54 & (110) & 3.358 & 100 & 1.120 & 7.615 & \multirow{10}{*}{8.074} & 17.244 & \multirow{10}{*}{4.748} & \multirow{10}{*}{3.184} \\
\hline & 33.88 & (101) & 2.645 & 87 & 1.170 & 7.417 & & 18.179 & & \\
\hline & 37.98 & $(200)$ & 2.368 & 27 & 1.250 & 7.023 & & 20.274 & & \\
\hline & 51.86 & (211) & 1.762 & 55 & 1.250 & 7.384 & & 18.341 & & \\
\hline & 54.56 & $(220)$ & 1.681 & 20 & 1.500 & 6.226 & & 25.796 & & \\
\hline & 57.90 & $(002)$ & 1.592 & 11 & 1.620 & 5.855 & & 29.167 & & \\
\hline & 62.02 & $(310)$ & 1.496 & 18 & 1.250 & 7.747 & & 16.660 & & \\
\hline & 64.76 & (112) & 1.439 & 20 & 1.500 & 6.552 & & 23.293 & & \\
\hline & 71.34 & (202) & 1.322 & 9 & 0.720 & 14.189 & & 4.967 & & \\
\hline & 78.70 & (321) & 1.215 & 10 & 1.000 & 10.732 & & 8.682 & & \\
\hline
\end{tabular}

The relative intensities of undoped and $\mathrm{Fe}$ doped $\mathrm{SnO}_{2}$ powders are calculated. The distance between crystalline planes values (d) are calculated by using following relation:

$2 \mathrm{~d} \cdot \sin \theta=\mathrm{n} \lambda$

Where $\mathrm{d}$ is distance between crystalline planes (A), $\theta$ is the Bragg angle, $\lambda$ is the wavelength of $\mathrm{X}$-rays $(\lambda=1.54056 \mathrm{~A})$.

The crystallite size is calculated from Scherrer's equation [7]:

$$
D=\frac{0.94 \lambda}{\beta \cos \theta}
$$

Where, $D$ is the crystallite size, $\lambda$ is the wavelength of X-ray, $\beta$ is full width at half maximum (FWHM) intensity in radians and $\theta$ is Braggs's angle.

The dislocation density is defined as the length of dislocation lines per unit volume and calculated by following equation [2]:

$$
\delta=\frac{1}{n^{2}}
$$

The lattice constants a and $\mathrm{c}$ for tetragonal phase structure are determined by the relation [8]:

$$
\frac{1}{d^{2}}=\frac{h^{2}+k^{2}}{a^{2}}+\frac{l^{2}}{c^{2}}
$$

Where $\mathrm{d}$ and $(\mathrm{hkl})$ are distance between crystalline planes and Miller indices, respectively.

The calculated lattice constants a, c values are given in table 1,2,3. It was seen that a, c and c/a match well with JCPDS data $(\mathrm{a}=\mathrm{b}=4.737 \mathrm{~A}$ and $\mathrm{c}=3.185 \mathrm{~A})$.

The change in peak intensities is basically due to the replacement of $\mathrm{Sn}^{4+}$ ions with $\mathrm{Fe}^{3+}$ ions in the lattice of the $\mathrm{SnO} 2$. This process leads to the movement of $\mathrm{Sn}^{4+}$ ions in interstitial sites.

Figure 3 represents variation of the average grain size with different concentrations of Fe doped $\mathrm{SnO} 2$ powdres. We observed from tables 1,2,3 that $6 \mathrm{wt} \% \mathrm{Fe}$ doped $\mathrm{SnO} 2$ is the closest value to undoped sample. 


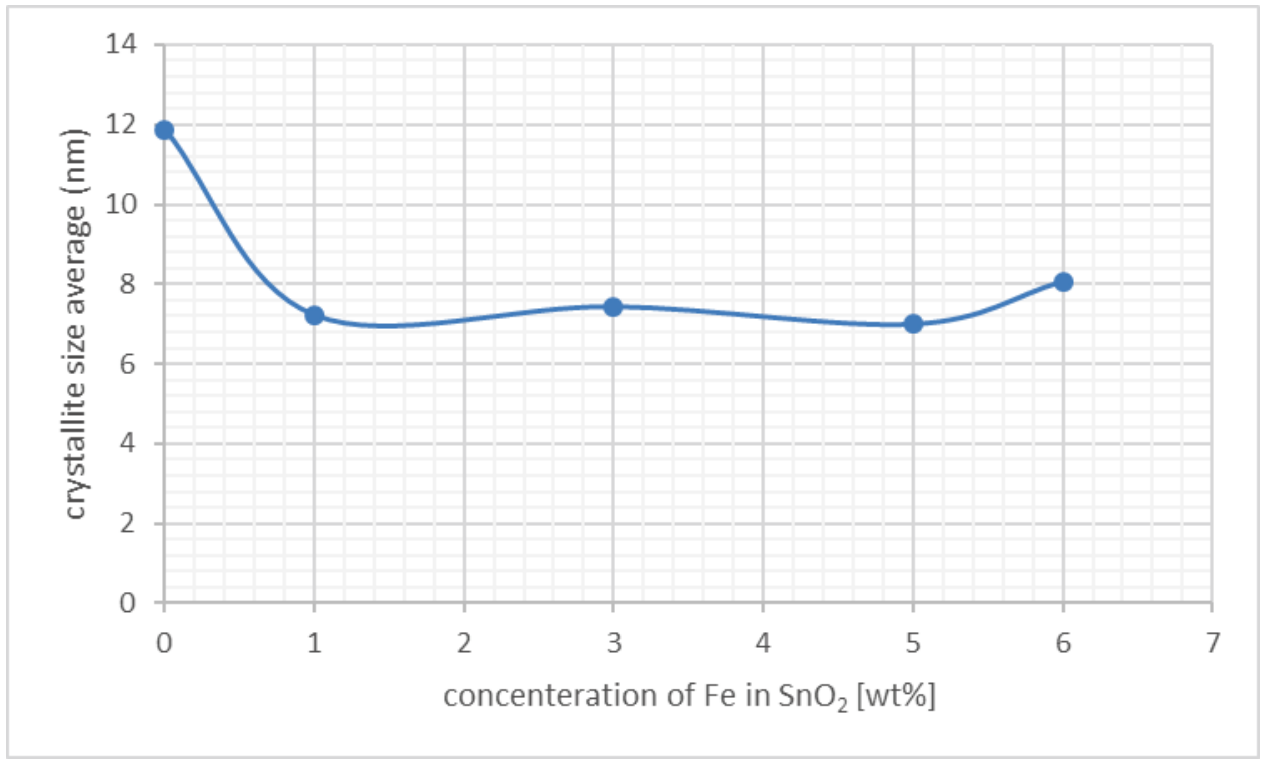

Fig. 3: variation of the average crystallite size with different concentrations of $\mathrm{Fe}$ doped $\mathrm{SnO}_{2}$ powders.

\section{4 .FT/IR analyses:}
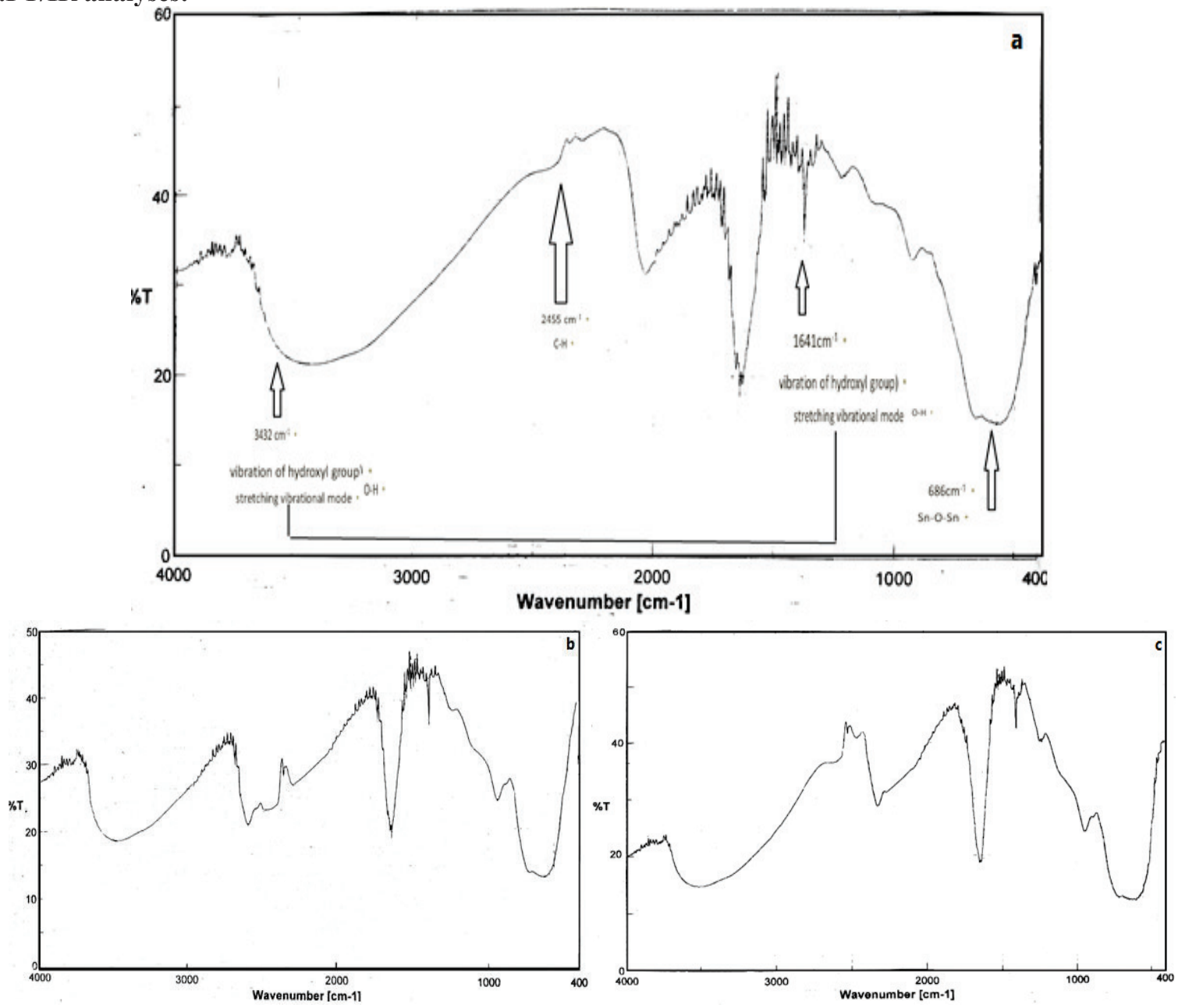

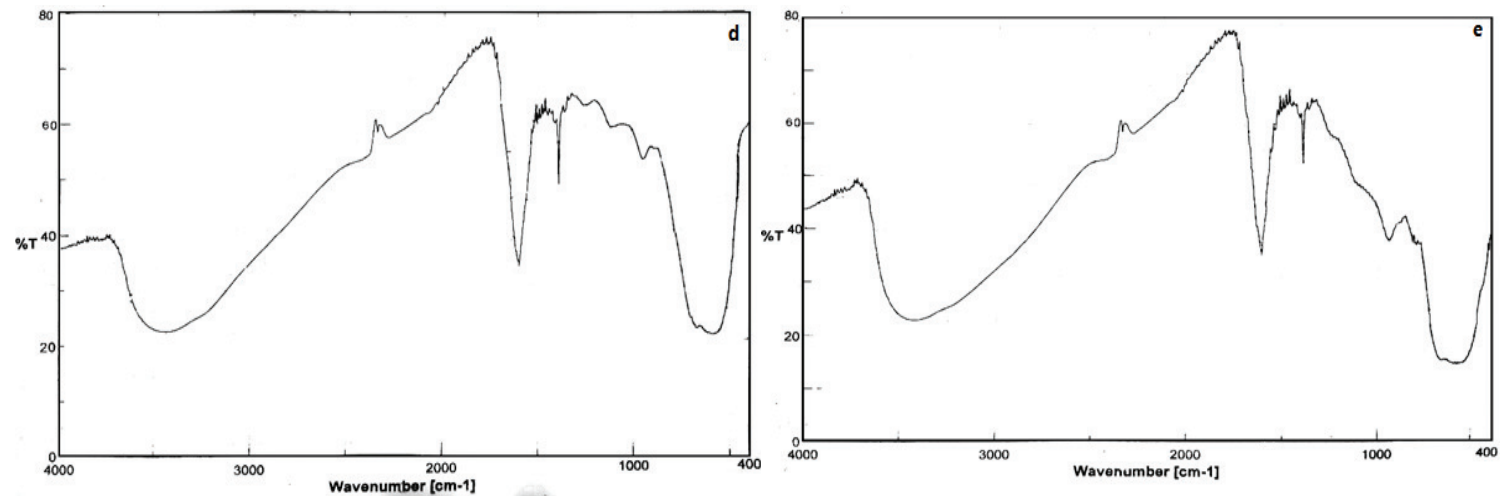

Fig. 4: FTIR analysis of pure and $\mathrm{Fe}$ doped $\mathrm{SnO}_{2}$ powder :(a) pure (b) $1 \mathrm{wt} \% \mathrm{Fe}$ doped $\mathrm{SnO}_{2}$, (c) $3 \mathrm{wt} \% \mathrm{Fe}$ doped $\mathrm{SnO}_{2}$, (d) 5 wt $\%$ Fe doped $\mathrm{SnO}_{2}$, (e) 6 wt $\%$ Fe doped $\mathrm{SnO}_{2}$

FTIR is a technique used to obtain information regarding chemical bonding and functional groups in a material. In the transmission mode, it is quite useful to predict the presence of certain functional groups which are adsorbed at certain frequencies; thus, it reveals the structure of the material. The band positions and numbers of absorption peaks depend on the crystalline structure, chemical composition, and also on morphology [9]. To investigate chemical groups on the surface of sintered samples, an FTIR analysis was carried out at room temperature over the wave number range of $400-4000 \mathrm{~cm}^{-1}$. There are several bands appearing in the wave number range $400-4000 \mathrm{~cm}^{-1}$. The broad absorption band at $3423 \mathrm{~cm}^{-1}$, the peaks at $2977 \mathrm{~cm}^{-1}$, and $1630 \mathrm{~cm}^{-1}$ are assigned to the vibration of hydroxyl group due to the absorbed/adsorbed water and show a stretching vibrational mode of $\mathrm{O}-\mathrm{H}$ group [10]. Absorption peaks observed around $2380 \mathrm{~cm}^{-1}$ belong to the stretching vibrations of $\mathrm{C}-\mathrm{H}$ bonds that could be due to the adsorption and interaction of atmospheric carbon dioxide with water during the firing process [11]. The bands observed in the range of $970-700 \mathrm{~cm}^{-1}$ are due to the vibration of $\mathrm{Sn}=\mathrm{O}$ and $\mathrm{Sn}-\mathrm{O}$ surface cation oxygen bonds [10]. The very strong absorption bands observed in the range of $420-700 \mathrm{~cm}^{-1}$ are attributed to the $\mathrm{Sn}-\mathrm{O}$ antisymmetric vibrations. In that region, the peak at $686 \mathrm{~cm}^{-1}$ are assigned to $\mathrm{Sn}-\mathrm{O}-\mathrm{Sn}$ vibrations, respectively [34]. The bands exhibited in the low wave number region 430-620 $\mathrm{cm}^{-1}$ are attributed to the $\mathrm{Sn}-\mathrm{O}$ stretching vibrations [13]. The Fe doping shifts the positions of the absorption bands. It has been previously reported that changes observed in the shape, width, and positions of FTIR peaks are attributed to the variation in the local defects, grain size and shape of the samples [14]. In all samples, the vibrations associated to $\mathrm{C}-\mathrm{H}$ and $\mathrm{O}-\mathrm{H}$ bonds are seen. This implies that the surface is highly active and adsorbed these molecules.

\section{Conclusion}

This paper presents a study of structural properties of $\mathrm{Fe}$ doped $\mathrm{SnO}_{2}$ powders prepared by solid state reaction method. X-ray diffraction patterns confirm that the samples have polycrystalline nature with tetragonal structure and show presence (110)، (101)، (200)، (111)، (210)، (211)، (220)، (002)، (310)، (112)، (301)، (202) and (321) planes in pure tin oxide sample. The all samples have preferred orientation along (110) plane. The average of crystallite size is within the range [11.877-7.004 nm] for all samples. It was defined that the lattice constants a, c for all the samples, were almost identical with JCPDS values, and the ratio c/a remained constant with increasing Fe dopant concentration. FTIR analysis revealed that the Fe doping manifests itself by a shift in $\mathrm{Sn}-\mathrm{O}$ absorption peaks positions.

\section{REFERANCE:}

[1] - Sakhta A.R. et al (2016), " Studying Effect of Mg Doping on the Structural Properties of Tin Oxide Thin Films Deposited by the Spray Pyrolysis Technique", Chemistry and Materials Research, 8, 12-18.

[2] - Turgut G., Keskenler E. F., Aydin S.; Sonmez E., Dogan S., Duzgun B. \& Ertugrul M. (2013), "Effect Of $\mathrm{Nb}$ Doping On Structural, Electrical And Optical Properties Of Spray Deposited SnO2 Thin Films", Super lattices and Microstructures, 56, 107-116.

[3] - Gandhi T., Babu R. \& Ramamurthi K. (2013) "Structural, Morphological, Electrical and Optical Studies Of Cr Doped SnO2 Thin Films Deposited By The Spray Pyrolysis Technique", Materials Science in Semiconductor Processing, 16, 427-479.

[4] -Vadivel S. \& Rajarajan G. (2015) "Effect Of Mg Doping On Structural, Optical And Photocatalytic Activity Of SnO2 Nanostructure Thin Films", Journal of Materials Science, 6, 730-738.

[5] - Jarzebski Z. \& Marton J. (1976) "Physical Properties of SnO2 Materials", Journal of the Electrochemical Society, 199-205.

[6] - Khanaa V. \& Mohanta K. (2013) "Synthesis and Structural Characterization of SnO2 Thin Films Prepared by Spray Pyrolysis Technique", International Journal of Advanced Research, 1(7), 666-669. 
[7] - Mariappan R., Ponnuswamy V. \& Suresh P. (2012) "Effect Of Doping Concentration On The Structural And Optical Properties Of Pure And Tin Doped Zinc Oxide Thin Films By Nebulizer Spray Pyrolysis (NSP) Technique", Superlattices and Microstructures, 52, 500-513.

[8] - Gurakar S., Serin T \& Serin N. (2014) "Electrical And Microstructural Properties Of (Cu, Al, In)-Doped SnO2 Films Deposited By Spray Pyrolysis", Advanced Materials Letters, 5(6), 309-314.

[9] - Ashokkumar.M,et al, (2014)," $\mathrm{Zn} 0 .{ }_{96-\mathrm{x}} \mathrm{Cu}_{0.04} \mathrm{Fe}_{\mathrm{x}} \mathrm{O}(0 \leqslant \mathrm{x} \leqslant 0.04)$ alloys - Optical and structural studies $)$, Superlattices and Microstructures, 69, 53-64.

[10] - Faisal.M, et al, (2015), "SnO 2 doped $\mathrm{ZnO}$ nanostructures for highly efficient photocatalyst", Journal of Molecular catalysis A: chemical, 39, 19-25.

[11] - Gnanam.S, Rajendran.V, (2010)," Preparation of Cd-doped $\mathrm{SnO}_{2}$ nanoparticles by sol-gel route and their optical properties", Journal of Sol-Gel Science and Technology, 56, 128-133.

[12] - Sharma A. ,et al. ,(2011), "Magnetic Properties of Fe and Ni Doped $\mathrm{SnO}_{2}$ Nanoparticles " Nanomaterials and Nanotechnology, 1, 29-33.

[13] - Mohamed S.H. ,et al, (2012), " $\mathrm{SnO}_{2}$ dendrites-nanowires for optoelectronic and gas sensing applications", Journal of Alloys and Compoundsvol, 510, 119-124.

[14] - Srinivas.K, (2011), "Structural, electronic and magnetic properties of $\mathrm{Sn}_{0.95} \mathrm{Ni}_{0.05} \mathrm{O}_{2}$ nanorods",_Nanoscale, 3, 642-653. 